\title{
Personas con discapacidad ante la enfermedad por coronavirus (COVID-19) en América Latina y el Caribe: situación y orientaciones
}

\section{Resumen}

En el contexto de la pandemia mundial de la enfermedad por coronavirus (COVID-19), la Comisión Económica para América Latina y el Caribe (CEPAL) está elaborando una serie de publicaciones cortas con recomendaciones de política relevantes para este período. En la presente nota se plantea una serie de recomendaciones para abordar el impacto del COVID-19 en las personas con discapacidad de la región.

\section{Introducción}

En América Latina y el Caribe residen mas de 70 millones de personas con discapacidad (CEPAL, 2014), que son diversas y experimentan discriminaciones múltiples y simultáneas debido a su situación socioeconómica, su género, edad, lugar de residencia, condición étnico-racial y estatus migratorio, entre otras. Las personas con discapacidad ya se encontraban entre las más excluidas en nuestras sociedades antes de la pandemia del COVID-19 y con la llegada de esta crisis sanitaria y sus devastadores impactos sociales y económicos estarán entre las más afectadas, junto con sus familias, lo que profundizará su situación de exclusión y marginación.

La asociación entre pobreza y discapacidad es uno de los factores que subyacen a la persistente exclusión de esta población. Los estudios sobre el vínculo entre discapacidad y pobreza coinciden en que se trata de una relación compleja e interdependiente, que opera a través de diversos canales. La discapacidad es una causa y, a su vez, una consecuencia de la pobreza. En términos generales, las personas que viven en situación de pobreza pueden tener un mal estado de salud y disponer de un acceso limitado a servicios para tratar esos problemas, carecer de una nutrición adecuada, residir en viviendas precarias sin acceso a agua potable y saneamiento, desempeñar trabajos peligrosos y vivir en áreas donde están expuestas a diferentes manifestaciones de violencia, todo lo cual puede aumentar su probabilidad de desarrollar alguna limitación (CEPAL, 2019a)

Asimismo, existen varios factores que pueden redundar en una mayor vulnerabilidad de la población con discapacidad a vivir en situación de pobreza. Desde un punto de vista de ciclo de vida, la exclusión de un niño o una niña con discapacidad del sistema educativo repercute en sus bajos logros educativos, lo que perjudica sus posibilidades posteriores de acceder a un trabajo decente, con ingresos suficientes y acceso a la protección social (CEPAL, 2019a). Esta exclusión se debe a barreras de diferente índole: de accesibilidad (por ejemplo, la accesibilidad física de las escuelas y del transporte), del contexto escolar (por ejemplo, la capacitación de profesores, materiales de aprendizaje, currículos adaptados), financieras y, sobre todo, a las barreras actitudinales de los profesores, los estudiantes y los padres y madres de los demás estudiantes (CEPAL, 2019b).

\section{Resumen}

Introducción

A. Impactos del COVID-19

en la población con

discapacidad en

América Latina y el Caribe

B. Recomendaciones

Bibliografía 
La inserción laboral de las personas con discapacidad se ve afectada negativamente por la falta de accesibilidad en la vía pública y en los lugares de trabajo, la falta de ajustes razonables necesarios para garantizar el ejercicio pleno del derecho al trabajo en igualdad de condiciones, así como por la discriminación y la persistencia de estereotipos negativos. En el ámbito laboral, algunos de los obstáculos que enfrentan las personas con discapacidad operan a nivel individual (baja calificación técnica y pocas habilidades blandas) y familiar (bajas expectativas familiares y sobreprotección familiar), barreras en el entorno (interrupciones en la cadena de accesibilidad desde el hogar hasta el lugar de trabajo) y los que enfrentan en los lugares de trabajo (desconocimiento y falta de experiencia con personas con discapacidad y una cultura poco inclusiva). Como consecuencia, las personas con discapacidad tienen tasas de desempleo más altas y una mayor probabilidad de no ser económicamente activas que las personas sin discapacidad. Si están trabajando, tienen mayor probabilidad de tener empleos mal remunerados, informales e inestables, con limitadas perspectivas profesionales (CEPAL, 2019b).

Por otra parte, aun con un mismo nivel de ingresos, los hogares que tienen entre sus miembros a una persona con discapacidad deben incurrir en mayores gastos debido a los costos asociados a los servicios de salud, la rehabilitación y la educación especializados, la compra y mantención de dispositivos de asistencia, los medicamentos y el transporte, entre otros. Además, cubrir las necesidades de cuidado de la persona con discapacidad puede obligar a algún miembro del hogar, frecuentemente una mujer, a retirarse del mercado laboral, lo que afecta los ingresos del hogar. Cuando no existen mecanismos de apoyo para cubrir o subvencionar estos costos y necesidades, deben ser costeados por la familia, lo que puede provocar o agravar situaciones de pobreza (CEPAL, 2019a).

\section{A. Impactos del COVID-19 en la población con discapacidad en América Latina y el Caribe}

A la fecha de redacción de esta nota había 62.526 casos confirmados de COVID-19 y 2.641 fallecidos a causa del virus en la región ${ }^{1}$. Si bien no se dispone de mucha información epidemiológica sobre los factores de riesgo asociados al COVID-19, se ha determinado que los casos y la mortalidad se concentran en personas mayores. Al momento, no hay datos sobre la situación de discapacidad en el caso de las personas enfermas ni en el de las personas fallecidas. Sin embargo, existe una relación positiva entre edad y discapacidad, por lo que es razonable pensar que algunas de las personas mayores que padecen de COVID-19 o fallecieron por esta causa tenían alguna discapacidad. Además de su perfil etario, las personas con discapacidad tienen un mayor riesgo ante el COVID-19 debido a sus limitadas posibilidades de protegerse del contagio o de buscar diagnóstico y tratamiento por la falta de información sobre el virus en formatos accesibles y la falta de accesibilidad en los establecimientos de salud. A nivel regional existe muy poca información sobre la población con discapacidad que se encuentra institucionalizada, debido a que el principal instrumento para recopilar información sobre esta población —-los censos de población y vivienda - no levantan información en estos establecimientos (CEPAL, 2014). No obstante, las personas con discapacidad que viven en instituciones y residencias comunitarias son especialmente vulnerables al COVID-19, dadas las limitadas opciones de distanciamiento social y las condiciones físicas de estos establecimientos.

Una de las áreas en las que ya se sienten los impactos de la pandemia es el empleo. Según la CEPAL, el sector más afectado por las medidas de distanciamiento social y cuarentena es el de los servicios, que depende de contactos interpersonales. En la región, los sectores que podrían sufrir las mayores contracciones - comercio, transporte, servicios empresariales y servicios sociales - proveen el 64\% del empleo formal. Además, el 53\% del empleo de la región se da en actividades informales, que se verán muy afectadas por basarse principalmente en contactos interpersonales (CEPAL, 2020). Si se tiene en cuenta que las personas con discapacidad ya tenían un tenue vinculo con el mercado laboral y una participación importante en el sector de servicios y en el empleo informal, es previsible que esta población se vea especialmente afectada por el desfavorable escenario del mercado laboral durante la crisis y el período de recuperación. Aunque los datos concretos

Datos de la Organización Mundial de la Salud (OMS, 2020) al 13 de abril 2020. Las cifras no incluyen información de los Estados Unidos y el Canadá. 
sobre esta realidad escasean, en una investigación en el Paraguay se estimó que el 40\% de las personas con discapacidad en ese país quedaron desempleadas tras el inicio de la cuarentena, con impactos significativos en los ingresos de sus hogares (ABC Color, 2020).

El ámbito escolar también presenta complejidades particulares para estudiantes con discapacidad y sus familias en el contexto de la pandemia. Según la CEPAL (2020), al 20 de marzo, 16 países (Argentina, Bolivia (Estado Plurinacional de), Chile, Colombia, el Ecuador, El Salvador, Guatemala, Honduras, Jamaica, Panamá, el Paraguay, el Perú, Santa Lucía, Trinidad y Tabago, el Uruguay y Venezuela (República Bolivariana de)) habían suspendido las clases en todos los niveles educativos, y el Brasil había aplicado cierres localizados de centros educativos. La interrupción de las actividades en centros educativos tendrá efectos significativos en el aprendizaje de estudiantes con discapacidad y podría afectar también su estado nutricional, ya que muchos estudiantes de hogares vulnerables, incluidos niños, niñas y adolescentes con discapacidad, dependen de programas de alimentación escolar. Aunque se han hecho planes para promover el uso de dispositivos digitales en los sistemas educativos, existen brechas en el acceso a las computadoras y a Internet y limitaciones en las habilidades para su uso en los hogares con personas con discapacidad (Ullmann y otros, 2018). El cierre de los establecimientos educativos y el traspaso de gran parte de la responsabilidad del acompañamiento y apoyo al aprendizaje de los docentes a los padres (principalmente las madres) también presenta un reto si estos no cuentan con las habilidades y técnicas didácticas para atender las necesidades de aprendizaje de sus hijos e hijas con discapacidad.

El confinamiento físico que se ha aplicado en muchos países de la región para frenar la transmisión del virus puede interrumpir el acceso a bienes y servicios esenciales para que las personas con discapacidad puedan mantener su bienestar. Esto es especialmente crítico en el caso de servicios de salud, rehabilitación y cuidados, pero también en el de medicamentos, pañales, dispositivos de asistencia y alimentos especiales, entre otros insumos. El confinamiento y las restricciones de desplazamiento también pueden agravar la situación de personas con ciertos tipos de discapacidad, por ejemplo, aquellas con trastorno del espectro autista (TEA), cuyas rutinas permiten disminuir el estrés y la ansiedad. La interrupción de esas rutinas debido al confinamiento puede afectar de manera negativa el bienestar de esas personas y sus familias. El confinamiento puede aumentar la exposición a la violencia intrafamiliar en el caso de las mujeres con discapacidad, que son víctimas de este tipo de violencia en mayor medida que las mujeres sin discapacidad.

\section{B. Recomendaciones}

Respetar los derechos fundamentales e inalienables de todas las personas en el contexto de la crisis y en el período de recuperación, independientemente de su situación de discapacidad, $y$ atender en particular a subgrupos de la población que pueden estar en especial situación de desventaja, como mujeres, niños, niñas y adolescentes con discapacidad. Esta pandemia ejerce presión sobre los escasos recursos de los sistemas de salud, por lo que es imprescindible garantizar la no discriminación en la provisión de bienes y servicios, y que todas las personas puedan acceder en igualdad de condiciones a programas y servicios de mitigación del gobierno.

Asegurar la accesibilidad a toda la información relacionada con la crisis. Esto incluye la información de salud pública para prevenir, detectar y tratar el COVID-19 e información sobre las medidas implementadas por los gobiernos para enfrentar y mitigar los impactos socioeconómicos de la pandemia, de modo que las personas con discapacidad pueden estar informadas sobre prestaciones a las que puedan acceder en el contexto de la crisis y en el período de recuperación. Esta información debe estar disponible en lenguaje de señas y en lenguaje sencillo y fácil de leer, en medios, modos y formatos accesibles, lo que incluye la tecnología digital, los subtítulos, los servicios de retransmisión y los mensajes de texto.

Asegurar la accesibilidad en espacios donde se llevan a cabo las pruebas para diagnosticar y tratar el COVID-19. Esto incluye la accesibilidad física de estas instalaciones, la posibilidad de adecuar la maquinaria hospitalaria y otros insumos médicos a personas con discapacidad que requieran tratamiento, así como el acceso a intérpretes de lenguaje de señas, entre otros. 
Reforzar las prestaciones de protección social no contributivas para las personas con discapacidad y sus familias. Muchos países de la región ya cuentan con pensiones o transferencias monetarias orientadas a personas con discapacidad para las que se aplican diferentes criterios de selección (por ejemplo, en lo referido a la imposibilidad de trabajar de la persona destinataria o los niveles de ingreso del hogar). Sin prejuicio de ello, los montos de estas pensiones o transferencias tienden a ser bajos, existen dificultades relacionadas con la selección de los destinatarios y los registros, y los procesos para certificar que la persona tiene una discapacidad son engorrosos (Ullmann y Atuesta, 2020). Los bajos montos de estas pensiones y transferencias no se corresponden con los elevados niveles de pobreza en hogares con personas con discapacidad y los costos adicionales de tener un miembro de la familia con una discapacidad, lo que justificaría montos de transferencias diferenciados y superiores a los destinados a la población sin discapacidad (Ullmann y Atuesta, 2020).

Velar por que las medidas tomadas para enfrentar la crisis y durante el período de recuperación, como las medidas sanitarias o las medidas sobre protección del empleo y continuidad educativa, incorporen la perspectiva de discapacidad. La pandemia ofrece a los países de la región una oportunidad para transversalizar en enfoque de discapacidad en las políticas públicas y, de este modo, resguardar los derechos y el bienestar de esta población.

Crear o ampliar espacios de participación y consulta con las organizaciones de personas con discapacidad. Durante todo el proceso de diseño e implementación de políticas para enfrentar y mitigar los impactos del COVID-19, estas organizaciones podrán responder y atender de manera adecuada las necesidades de las personas con discapacidad, respetando sus derechos y dignidad. Estas instancias de consulta también pueden arrojar luz sobre las posibilidades de las personas con discapacidad y sus agrupaciones de contribuir a enfrentar el COVID-19.

Asegurar la continuidad del trabajo, la educación y la prestación de servicios de rehabilitación para las personas con discapacidad a través del uso de tecnologías de la información y las comunicaciones (TIC). Si bien las TIC pueden ser una herramienta fundamental para limitar el impacto negativo del confinamiento y el distanciamiento físico en las vidas de personas con discapacidad y sus familias, es necesario fortalecer el acceso a las tecnologías desde el punto de vista económico. En este sentido, los gobiernos deberían explorar opciones para subsidiar en el corto plazo la adquisición de tecnologías y capacitación para su uso en el caso de las personas con discapacidad. Alternativamente, se puede explorar el uso de otros dispositivos, como la radio y la televisión, a los cuales hogares con personas con discapacidad sí pueden tener acceso

Proveer apoyo psicosocial a personas con discapacidad y sus familias y potenciar las redes de apoyo a personas con discapacidad.

Flexibilizar las restricciones a la circulación en la vía publica para personas con discapacidad y considerar la posibilidad de establecer horarios de atención diferenciados en los comercios para personas con discapacidad y otros grupos vulnerables al virus.

Mejorar la información estadística recopilada durante y después de la crisis, de manera que los países cuenten con información desagregada sobre los impactos diferenciados de la pandemia del COVID-19 sobre determinados grupos poblacionales, incluidas las personas con discapacidad. 


\section{Bibliografía}

ABC Color (2020), "El 40\% de personas con discapacidad quedaron desempleadas durante cuarentena", 6 de abril [en línea] https://www.abc.com.py/nacionales/2020/04/06/ el-40-de-personas-con-discapacidad-quedaron-desempleadas-durante-cuarentena/.

CEPAL (Comisión Económica para América Latina y el Caribe) (2020), "América Latina y el Caribe ante la pandemia del COVID-19: efectos económicos y sociales", Informe Especial, N 1, Santiago.

(2019a), Nudos críticos del desarrollo social inclusivo en América Latina y el Caribe. antecedentes para una agenda regional (LC/CDS.3/3), Santiago. (2019b), Panorama Social de América Latina, 2018 (LC/PUB.2019/3-P), Santiago.

(2014), Informe regional sobre la medición de la discapacidad: una mirada a los procedimientos de medición de la discapacidad en América Latina y el Caribe (LC/L.3860(CE.13/3)), Santiago.

OMS (Organización Mundial de la Salud) (2020), "Coronavirus disease 2019 (COVID-19) situation report-84" [en línea] https://www.who.int/docs/default-source/coronaviruse/ situation-reports/20200413-sitrep-84-covid-19.pdf?sfvrsn=44f511ab_2.

Ullmann, H. y B. Atuesta (2020), "Las transferencias monetarias no contributivas: un instrumento para promover los derechos y el bienestar de la población infantil con discapacidad en América Latina y el Caribe", Documentos de Proyectos, Comisión Económica para América Latina y el Caribe (CEPAL)/Fondo de las Naciones Unidas para la Infancia (UNICEF), por aparecer.

Ullmann, H. y otros (2018), "Information and communications technologies for the inclusion and empowerment of persons with disabilities in Latin America and the Caribbean", Documentos de Proyectos (LC/TS.2018/48/-*), Santiago, Comisión Económica para América Latina y el Caribe (CEPAL).

Este documento es parte de un conjunto de informes elaborados por la Comisión Económica para América Latina y el Caribe (CEPAL) sobre la evolución y los efectos de la pandemia del COVID-19 en América Latina y el Caribe. Fue preparado por la División de Desarrollo Social, a cargo de Simone Cecchini, bajo la coordinación general de Alicia Bárcena, Secretaria Ejecutiva de la CEPAL.

Copyright (C) Naciones Unidas, 2020 